\title{
Persistent gene expression in mouse vagina exposed neonatally to diethylstilbestrol
}

\author{
S Miyagawa',2,3, A Suzuki ${ }^{3}$, Y Katsu,3,3 M Kobayashi'1,2,3, M Goto ${ }^{3}$, H Handa $^{4}$, \\ H Watanabe ${ }^{2,3}$ and T Iguchi ${ }^{1,2,3}$ \\ ${ }^{1}$ School of Life Science, The Graduate University for Advanced Studies, 5-1 Higashiyama, Myodaiji, Okazaki, 444-8585, Japan \\ ${ }^{2}$ Center for Integrative Bioscience, Okazaki National Research Institutes, 5-1 Higashiyama, Myodaiji, Okazaki, Aichi 444-8585, Japan \\ ${ }^{3}$ Core Research for Evolutional Science and Technology (CREST), Japan Science and Technology Corporation, 4-1-8 Motomachi, Kawaguchi, \\ 332-0012, Japan \\ ${ }^{4}$ Frontier Collaborative Research Center, Tokyo Institute of Technology, 4259 Nagatsuta, Yokohama, 226-8503, Japan
}

(Requests for offprints should be addressed to T Iguchi, Center for Integrative Bioscience, Okazaki National Research Institutes, 5-1 Higashiyama, Myodaiji, Okazaki, Aichi 444-8585, Japan; Email: taisen@ nibb.ac.jp)

\begin{abstract}
Developmental exposure to a synthetic estrogen, diethylstilbestrol (DES), induces carcinogenesis in human and laboratory animals. In mice, neonatal DES treatment induces persistent proliferation and keratinization of the vaginal epithelium, even in the absence of the ovaries, resulting in cancerous lesions later in life. To understand the mechanisms underlying this persistent cell proliferation and differentiation, we characterized the gene expression patterns in the neonatally DES-exposed mouse vagina using DNA microarray and real-time quantitative RT-PCR. We found that genes related to cellular signaling, which are candidates for mediating the persistent proliferation and differentiation, were altered, and genes related to the immune system were decreased in the neonatally DES-exposed mouse vagina. We also noted high expression of interleukin-1 (IL-1)-related genes accompanied by phosphorylation of JNK1. In addition, expression IGF-I and its binding proteins was modulated and led to phosphorylation of IGF-I receptor and Akt, which is one of the downstream factors of IGF-I signaling. This led us to characterize the expression as well as the phosphorylation status of IL-1 and IGF-I signaling pathway components which may activate the phosphorylation cascade in the vagina of mice exposed neonatally to DES. These findings give insight into persistent activation in the vagina of mice exposed neonatally to DES.
\end{abstract}

Journal of Molecular Endocrinology (2004) 32, 663-677

\section{Introduction}

Estrogens tightly regulate cell proliferation and differentiation in target organs, particularly the reproductive tracts (oviduct, uterus and vagina) and mammary gland. The vaginal epithelium is a particularly intriguing model for estrogen-regulated gene expression. It undergoes characteristic changes from non-keratinized to a fully keratinized epithelium depending on the levels of the endogenous estrogen, estradiol $\left(\mathrm{E}_{2}\right)$, during the estrous cycle. Under this process, $\mathrm{E}_{2}$-induced cell proliferation is restricted to the basal layer. The suprabasal cells are no longer mitogenic but differentiate while moving up through the epithelium; finally, the apical cells exhibit keratiniz- ation, losing their nuclei and cytoplasm and substituted by the keratin proteins. The fully stratified and keratinized epithelium in the vagina resembles epidermis in the skin, however, again, differentiation of vaginal epithelium is regulated by estrogen.

Long-term estrogenic stimulation is a known risk factor for carcinogenesis in laboratory animals and humans (Marselos \& Tomatis 1992a,b). In humans, transplacental exposure to a synthetic estrogen, diethylstilbestrol (DES), which was routinely prescribed to pregnant women for preventing miscarriages in 1940 s to the 1970 s, induces vaginal clear-cell adenocarcinoma in young women (Herbst et al. 1971). As generations of women exposed to DES approach menopause, concern has 
arisen about their health risk, because it has been hypothesized that in utero DES exposure influences the incidences of breast cancer, squamous neoplasia of the cervix and vagina, and vaginal clear-cell adenocarcinoma later in life (Herbst 2000, Hatch et al. 2001, Palmer et al. 2002). Rodent models of DES exposure have been developed to understand the mechanistic basis of DES effects in humans. In mice, developmental exposure to estrogens within a critical developmental period elicits various permanent alternations in female reproductive tracts. For example, in the vagina, neonatal estrogen administration induces persistent cell proliferation and cornification of vaginal epithelium even after ovariectomy (OVX), resulting in hyperplastic lesions later in life (Takasugi et al. 1962, Forsberg 1979, McLachlan et al. 1980). We previously reported that persistent erbB receptor phosphorylation and sustained expression of epidermal growth factor-like growth factors contributed to persistent action in the neonatally DES-exposed vagina (Miyagawa et al. 2004). However, the underlying mechanisms remain unknown, therefore, additional factors must be present. In order to understand the underlying mechanisms of persistent action, it is important to understand cellular events, such as mRNA/protein expression and the phosphorylation status of signaling molecules.

In this report, we characterized the mRNAs expression patterns using DNA microarray and real-time quantitative RT-PGR (Q-PGR). In the vagina of mice exposed neonatally to DES, expressions of various genes were modulated, and interleukin-1 (IL-1) and insulin-like growth factor-I (IGF-I) signaling were activated without estrogen stimulation. In particular, IGF-I receptor (IGF-IR) and its downstream factor, Akt, were phosphorylated, which may lead to persistent cell proliferation and differentiation in the vagina. In addition, genes related to the immune system were suppressed in the neonatally DES-exposed mouse vagina. These findings give insight into persistent phenomena in vaginas exposed neonatally to DES in mice, and also in humans.

\section{Materials and methods}

\section{Animals and treatments}

Female C57BL/6J mice were maintained under $12 \mathrm{~h}$ light: $12 \mathrm{~h}$ darkness at $23-25^{\circ} \mathrm{C}$ and fed laboratory chow (CE-2; CLEA, Tokyo, Japan) and tap water freely. All procedures were approved by the Institutional Animal Care and Use Committee at the National Institute for Basic Biology, Okazaki National Research Institutes.

Female newborn mice were given a daily s.c. injection of $2.5 \mu \mathrm{g}$ DES (Sigma)/g body weight (BW) per day dissolved in sesame oil (Kanto Chemical, Tokyo, Japan) or the vehicle alone beginning from day 0 (the day of birth) to day 4 . These mice underwent OVX at day 46 and were killed at day 60 (referred to as neoDES mouse) (see Fig. 1A). For examining effects of estrogen and IGF-I, a single injection of $50 \mu \mathrm{g} \mathrm{E}_{2}$ (Sigma) or $500 \mu \mathrm{g}$ long R3 IGF-I (JRH Biosciences, Lenexa, TS, USA)/g BW was given to 60-day-old mice, which underwent OVX at day 46, and were killed $0.5,1,3,6,12,24,36$ and $48 \mathrm{~h}\left(\mathrm{E}_{2}\right)$ or $15 \mathrm{~min}$ (IGF-I) after the injection. Some mice underwent OVX at day 46 and were treated with a daily injection of $2.5 \mathrm{ng}$ DES/g BW per day for 5 days, then killed $24 \mathrm{~h}$ after the last injection. This treatment was sufficient to induce stratified and keratinized vaginal epithelium in adult OVX mice. For tissue separation, neoDES vaginas were cut into small pieces, placed into 1\% trypsin in Hanks' balanced salt solution and incubated at $4{ }^{\circ} \mathrm{C}$ for $90 \mathrm{~min}$. Then, the vaginal epithelium and stroma were separated mechanically using fine surgical forceps. More than three mice were pooled per each experimental group.

\section{Immunohistochemistry}

Tissues were fixed in neutral buffered 10\% formalin, embedded in paraffin and sectioned at $6 \mu \mathrm{m}$. Deparaffinized sections were incubated in $0 \cdot 3 \% \mathrm{H}_{2} \mathrm{O}_{2}$ in methanol for $15 \mathrm{~min}$ to eliminate endogenous peroxidases. After washing with PBS, the sections were stained with Histofine (Nichirei, Tokyo, Japan) according to the manufacturersupplied protocol. Antibody for $\mathrm{Ki}-67$ antigen was obtained from Novocastra Laboratories Ltd (Newcastle upon Tyne, UK). The sections were incubated at 1:1000 dilutions in PBS containing $1 \%$ BSA (Sigma) for $60 \mathrm{~min}$ at room temperature.

\section{DNA microarray analysis}

Preparation of cRNA and microarray analysis were essentially performed as described previously 
(Watanabe et al. 2003). Total RNA was isolated with the TRIZOL reagent (Invitrogen) and purified using the RNeasy kit (Qiagen). Total RNA (10 $\mu \mathrm{g})$ was converted into double-strand cDNA using the SuperScript Choice System (Invitrogen) with the T7-(dT) 24 primer (Amersham), which was used for first-strand cDNA synthesis. Biotin-labeled cRNA was synthesized using the ENZO BioArray HighYield RNA transcript labeling kit (Amersham). The cRNA was purified using RNeasy kit and partly hydrolyzed in fragmentation buffer $(40 \mathrm{mM}$ Tris, $100 \mathrm{mM}$ potassium acetate and $30 \mathrm{mM}$ magnesium acetate, $\mathrm{pH} 8 \cdot 1$ ) by $94{ }^{\circ} \mathrm{C}$ heat treatment for $35 \mathrm{~min}$. The fragmented cRNA was mixed with hybridization buffer containing 100 mM 2-(N-morpholino)ethanesulfonic acid, $1 \mathrm{M}$ $\mathrm{NaCl}, 20 \mathrm{mM}$ EDTA and 0.01\% Tween-20, and control oligonucleotides. The quality of the cRNA was assessed by analysis with Test 3 array (Affymetrix; Amersham) containing housekeeping genes. All preparations met Affymetrix's criteria for use on their expression arrays. After checking the quality of the cRNAs, $15 \mu \mathrm{g}$ cRNA were hybridized to the high-density oligonucleotide arrays, Murine U74A GeneChip Expression Arrays (Affymetrix; the references to array design are available on the manufacturer's website, http://www.affymetrix. com) for $16 \mathrm{~h}$ at $45^{\circ} \mathrm{C}$. The arrays were then washed, stained with streptavidin-phycoerythrin (Molecular Probes, Eugene, OR, USA) in an Affymetrix fluidix station and scanned with an argon-ion laser confocal scanner (Affymetrix).

Data were analyzed with GeneChip software Microarray Suite 5.0 (Affymetrix) as described elsewhere (Lockhart et al. 1996). Briefly, each gene is represented by 20 perfectly matched (PM) and one-base-mismatched (MM) 25 base oligonucleotides. As the MM probes are used to detect background level and cross-hybridization signals, the relative level of the gene expression is represented by differences between the levels of fluorescent intensity of the PMs and MMs, which are averaged into the so-called average difference. To normalize the data, the average differences were adjusted to produce an average intensity that equaled 2500.

The signals obtained from experimental groups were performed twice, independently, and the differences in intensities were calculated. In order to maintain reproducibility, we only selected the genes whose expression level changes were less than 2-fold between two independent experiments under the same conditions and average values were used as gene expression levels. Genes showing 3-fold alteration in the neonatally DES-treated mice as compared with oil controls were selected and analyzed further.

\section{Real-time Q-PCR}

Changes in gene expression were confirmed and quantified using Q-PCR using the ABI Prism 5700 Sequence Detection System with SYBR Green Master Mix according to the manufacturer's instructions (Applied Biosystems, Foster City, CA, USA). Total RNA $(2 \cdot 5 \mu \mathrm{l})$ was used in the RT reaction carried out with SuperScript II reverse transcriptase (Invitrogen) and random primers (9-mer; Takara, Ohtsu, Japan) for $60 \mathrm{~min}$ at $42{ }^{\circ} \mathrm{C}$. PGR conditions were as follows: $50^{\circ} \mathrm{C}$ for $2 \mathrm{~min}$, $95{ }^{\circ} \mathrm{C}$ for $10 \mathrm{~min}$, and 40 cycles of $95{ }^{\circ} \mathrm{C}$ for $15 \mathrm{~s}$ and $60{ }^{\circ} \mathrm{C}$ for $1 \mathrm{~min}$ in $15 \mu \mathrm{l}$ volumes. The primers were chosen to amplify short PCR products (less than 100 bp) with the assistance of Primer Express software (Applied Biosystems). The representative primer sequences are as follows: IL- $1 \alpha$ (X01450), AGG AGA GCG GGG TGA CAG TAT, TCA CTG AAA CTG AGG CGT CTG TT; IL-1 $\beta$ (X04964), TGA GGG AGG CAG TAT CAG TCA TT, GGA AGG TCG AGG GGA AAG A; IL-1 receptor type I (IL-1RI) (M20658), CCT GTG CGG GAC ACT AAG GA, GCG CAC TTT TGG CAT GCT A; IL-1 RII (X59769), GTT TAT CTG GGG TGG TTA CGA A, CAA AAA TGA GGG ACA CTT GGA C; IL-1 receptor antagonist (IL-1 ra) (L32838), GCT TCT GAT GGT TGT GTT TGA TTG A, GTT GGA TCT TGG AGG GTG TTT; IL-1-like protein 1 (IL-1L1) (AJ250429), GGG CGA AGG AAT CAA AGA GG, GGG ATT GGA AGG TGG AGG TA; IGF-I (X04480), TTG AGT TGG TGT GTG GAC CGA G, TCG ACA ATG CGT GTG TGA GGT G; keratinocyte growth factor (KGF) (NM_008008), GAA AGG GAC CGA GGA GAT GAA, TGA TTG CGA CAA TTG CAA CTG; and ribosomal protein L8 (U67771), ACA GAG GAG TTG TTG GTG TTG, GAG GAG TTG GTG TTT GGG TTG T. The other primer sequences are available upon request. Melting curve analysis using 5700 software was performed to confirm the primer efficiency. Relative RNA equivalents for each sample were obtained by 
standardization of ribosomal protein L8 levels. The expression of granulocyte-macrophage colony stimulation factor (GM-CSF) was quantified using the ABI Prism 7000 System with FAM-labeled Taqman probe and primers (Assays-on-Demand Gene Expression Products; Applied Biosystems) because an efficient primer set could not be established using the SYBR Green Q-PGR. The relative RNA equivalent for GM-CSF was obtained by standardization of ribosomal protein S5 levels. For quantifying gene expression on DNA microarray data, more than two pools of samples per group were run in triplicate to determine sample reproducibility, and the average relative RNA equivalents per sample were used for further analysis. All values are represented as fold change compared with the control treatment group average as $1 \cdot 0$. For analyses of IGF-I, KGF, GM-CSF and IL-1-related genes, three pools of samples per group were used. Statistical analysis was performed using Student's $t$-test or Welch's $t$-test followed by an F-test. Points of statistical significance vs control are indicated by asterisks $\left(^{*}\right)$, with $P<0 \cdot 05$.

\section{Protein preparation and immunoblotting}

Dissected mouse vaginas were immediately homogenized in buffer $(20 \mathrm{mM}$ Hepes, $2 \mathrm{mM}$ EDTA, $2 \mathrm{mM}$ EGTA, $250 \mathrm{mM}$ sucrose, $2 \mathrm{mM} \mathrm{Na} \mathrm{VO}_{4}$, $2 \mathrm{mM} \mathrm{NaF}, 100 \mathrm{mM} \quad \beta$-glycerophosphate and protease inhibitor cocktail (Complete Mini; Boehringer Mannheim, Mannheim, Germany), $\mathrm{pH}$ 7.5). The homogenates were centrifuged at $900 \boldsymbol{g}$ for $15 \mathrm{~min}$ at $4^{\circ} \mathrm{C}$. Supernatant fluids were recentrifuged at $105000 \mathrm{~g}$ for $60 \mathrm{~min}$ and the resulting supernatant fluids were used for detection for stress-activated protein kinase/c-Jun N-terminal kinase (SAPK/JNK) and Akt. The pellets were suspended in homogenization buffer without sucrose but containing $250 \mathrm{mM} \mathrm{NaCl}$ and $1 \%$ Triton X-100, and they were used for detection of IGF-IR. Protein contents were determined using the Bradford Assay (Protein Assay reagent; BioRad, Hercules, CA, USA).

After electrophoresing on SDS-polyacrylamide gels, proteins were subsequently transferred to nitrocellulose membranes. The membranes were preincubated with 3\% BSA in Tris-buffered saline contained $0 \cdot 1 \%$ Tween-20 (TBST) overnight at $4{ }^{\circ} \mathrm{C}$. Incubations with each antibody were performed at a dilution of 1:1000 at room temperature for $2 \mathrm{~h}$ in TBST (IGF-IR, SAPK/ JNK, Akt, phospho-SAPK/JNK and phospho-Akt) or $1: 1000$ at $4{ }^{\circ} \mathrm{C}$ overnight in TBST and $5 \%$ BSA (phospho-IGF-IR). Anti-IGF-IR antibody was obtained from Santa Cruz Biotechnology (Santa Cruz, CA, USA), and anti-SAPK/JNK, -Akt, -phospho-SAPK/JNK (Thr183/Tyr185 of human sequence corresponding to Thr183/Tyr185 of mouse sequence), -IGF-IR (Tyr 1131 to Tyr 1163 of mouse sequence) and -phospho-Akt (Ser 473 and Thr 308 of mouse sequence) antibodies were obtained from Cell Signaling Technology (Beverly, MA, USA). For experimental reproducibility, more than two pools of experimental groups were used. Signals were detected with an ECL kit (Amersham).

\section{Results}

\section{Histology of the neoDES vagina}

Persistent epithelial proliferation and keratinization were induced by five daily injections of DES from the day of birth as shown in Fig. 1A. The vaginal epithelium of neonatally oil-injected 60-day-old OVX mice (control) was composed of two or three layers of cuboidal cells, whereas the epithelium of the age-matched, neonatally DES-exposed, OVX mice (neoDES) exhibited stratification and superficial keratinization (Fig. 1B). In the neoDES vagina, basal epithelial cells showed high proliferative activity, which was confirmed by Ki-67 antigen immunostaining (Fig. 1C). In contrast, the basal epithelial cells of control animals did not.

\section{Microarray analysis of gene expression changes in the neoDES vagina}

Neonatal DES treatment causes persistent cell proliferation and differentiation, however, molecular mechanisms underlying estrogen-induced changes have not been elucidated. We compared gene expression of vaginas of OVX mice treated neonatally with either oil (control) or DES (neoDES) using DNA microarray. The oligomicroarray system (Affymetrix GeneChip - Murine U74A) was used for analysis of the gene expression pattern. The scanned data were analyzed and fold changes in expression levels were determined in the 9977 genes. The genes showing changes in expression (increased or decreased more than 
A
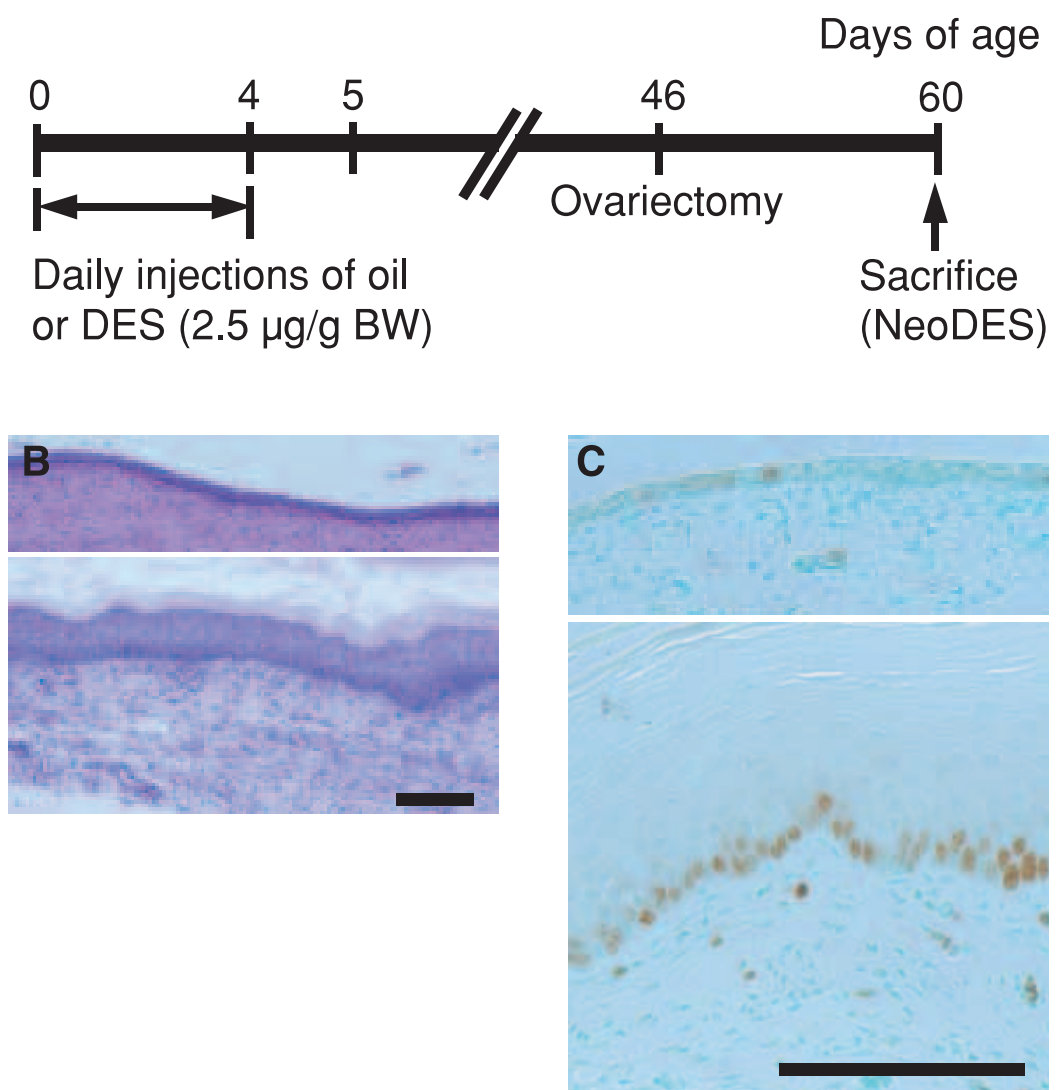

Figure 1 (A) Treatment timeline of neonatal DES treatment and histological analysis. Female newborn mice were given five daily injections of $2.5 \mu \mathrm{g} \mathrm{DES} / \mathrm{g}$ BW or the vehicle alone from day 0 . They underwent OVX at day 46 and were killed at day 60. (B) Histology of vaginas from a 60-day-old OVX control (upper panel) and neoDES mice (lower) at low magnification. The sections were stained with hematoxylin and eosin. Scale bar $=100 \mu \mathrm{m}$. (C) Immunohistochemical staining of Ki-67 antigen with methyl green. The samples are from control (upper) and neoDES vaginas (lower). Scale bar $=100 \mu \mathrm{m}$.

3-fold) between control and neoDES vaginas were selected for further analysis. Thus, 115 increased genes (22 genes were expressed sequence tags (ESTs)) and 160 decreased genes (53 genes were ESTs) were identified by microarrays.

As expected, the expression of cytokeratin (CK) mRNAs and components of the cornified cell envelope were highly increased in the neoDES vagina (Table 1). Expression of marker genes related to keratinization was also increased; e.g. metallothionein IV (93.7-fold compared with controls) (Quaife et al. 1994), transglutaminase 3 (17·1-fold) (Kim et al. 1993), peptidylarginine deiminase IV (5·1-fold) (Ishigami et al. 1998). In contrast, expression of CK8 and CK18, which are both preferentially expressed in simple epithelial cells and basal cells in stratified epithelium, was decreased (Bosch et al. 1988). Intriguingly, expression of several genes related to the immune system were decreased in neoDES vaginas, as compared with controls (Table 2).

In order to further characterize the neoDES vagina, we focused on aberrant signaling related to proliferation and differentiation of vaginal epithelium. Hence, genes involved in signal transduction were studied in detail. As to genes related to cell signaling from microarray data, Q-PGR was employed to validate the microarray data and 
Table 1 List of increased and decreased genes related to the cytoskeleton in vaginas of mice exposed neonatally to DES

\begin{tabular}{llc} 
& Gene name & Fold changes \\
\cline { 2 - 3 } Accession no. & & \\
AF053235 & Cytokeratin 16 (CK16) & 2352 \\
Y09227 & Small proline-rich protein (SPR) 3 & 1552 \\
X91825 & SPR 1b & 326 \\
X99251 & Repetin & 111 \\
J03458 & Filaggrin & 104 \\
AJ005566 & SPR 2H & $87 \cdot 4$ \\
AJ005564 & SPR 2F & $64 \cdot 0$ \\
AJ005561 & SPR 2C & $26 \cdot 9$ \\
V00830 & CK10 & $24 \cdot 3$ \\
AB012042 & CK63 & $24 \cdot 3$ \\
K02108 & Keratin complex 2, gene 6A & $24 \cdot 3$ \\
AJ005562 & SPR 2D & $23 \cdot 4$ \\
X03491 & CK4 & $19 \cdot 0$ \\
U09189 & Loricrin & $17 \cdot 8$ \\
AF057156 & SPR 1A & $16 \cdot 0$ \\
AJ005559 & SPR 2A & $16 \cdot 0$ \\
AJ005560 & SPR 2B & $12 \cdot 6$ \\
M10937 & CK1 & $12 \cdot 6$ \\
AJ005568 & SPR 2J & $10 \cdot 6$ \\
AJ005569 & SPR 2K & $8 \cdot 9$ \\
U13921 & CK13 & $8 \cdot 6$ \\
AB012033 & CK6a & $8 \cdot 6$ \\
AJ005559 & SPR 2A & $7 \cdot 7$ \\
AB017202 & Nidogen-2 & $7 \cdot 5$ \\
AJ005567 & SPR 2I & $6 \cdot 7$ \\
AJ005565 & SPR 2G & $3 \cdot 6$ \\
AJ005563 & SPR 2E & $3 \cdot 5$ \\
M22832 & CK18 & $-23 \cdot 4$ \\
X15662 & CK 8 & $-8 \cdot 6$ \\
M12481 & Actin beta & $-6 \cdot 1$ \\
& & \\
& &
\end{tabular}

quantify the expression of putative targets of neonatal DES exposure. Table 3 shows a list of genes whose expression was changed more than 3-fold as measured by Q-PCR. The list includes growth factors and cytokines, membrane receptors/proteins, intracellular/signaling factors, transcription factors and their regulators, nuclear proteins, protease inhibitors and miscellaneous genes.

We have analyzed the factors involved in vaginal cell proliferation and differentiation focusing on growth factors and cytokines (Miyagawa et al. 2004). The novel finding in the present study is that genes related to the IL-1 system (IL-1L1 and IL-1 RII) were increased in expression in the neoDES vagina. Thus, the IL-1 system is also possibly involved in the persistent vaginal epithelial cell proliferation and differentiation. We also found that several growth factor-binding proteins were increased (IGF-binding protein (IGFBP)-2 and fibroblast growth factor (FGF)-binding protein (FGFBP)-1) and decreased (IGFBP-3 and latent transforming growth factor- $\beta$ binding protein (LTBP)-2) in the neoDES vagina as compared with controls. As to IGF-I signaling, its receptor (IGF-IR) was decreased in the neoDES vagina. It is a common property of receptor tyrosine kinase that ligand binding and phosphorylation of receptor ultimately result in downregulation (Pastan \& Willingham 1983). Although their ligands (IGFs) did not show 3-fold change on DNA array, these growth factors systems are possibly involved in persistent proliferation of epithelial cells in the neoDES vagina. To confirm this hypothesis, we further analyzed two signaling pathways, the IL-1 and IGF-I cascades, in the neoDES vagina. 
Table 2 List of increased and decreased genes related to the immune system in vaginas of mice exposed neonatally to DES

\section{Gene name}

\section{Accession no.} AF109905

L38444

AV092014

AF039663

$\mathrm{X} 13333$

V00746

U69488

AB001489

AF076482

M58156

X00246

$\mathrm{X} 16202$

AF109906

X58609

AJ132098

AF029215

X58861

M18837

Vanin-1

MRC OX-2
MHC class III regions Hsc70t

T cell-specific guanine nucleotide triphosphate-binding protein (TGTP)

Peptidoglycan recognition protein (Pglyrp)

AC133 antigen homolog

CD14 antigen

MHC class I antigen $\mathrm{H}-2 \mathrm{~K}$

Viral envelope like protein (G7e)

Phosphatidylinositol glycan class $R$

Peptidoglycan recognition protein precursor (Pgrp)

MHC class I antigen $\mathrm{H}-2 \mathrm{~K}-\mathrm{b}$

MHC class I antigen with a Set 1 repetitive element

MHC class I antigen Q4

$\mathrm{MHC}$ class III region RD

MHC class I antigen Q2-k

Complement component 1 q subcomponent $\alpha$

MHC class I Q4 beta-2-microglobulin
Fold changes

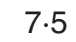

$-8 \cdot 0$

$-6 \cdot 7$

$-5.9$

$-5 \cdot 7$

$-5 \cdot 5$

$-5 \cdot 3$

$-4.9$

$-4.9$

$-4.4$

$-4 \cdot 4$

$-4.3$

$-4 \cdot 1$

$-4 \cdot 0$

$-3.9$

$-3.7$

$-3 \cdot 6$

$-3.5$

\section{IL-1 signaling in the neoDES vagina}

Cytokine networks regulate epidermal tissue homeostasis and keratinocyte proliferation and differentiation (Schroder 1995). Using an in vitro skin equivalent model, IL-1 induction regulates epidermal proliferation and differentiation through the induction of KGF/FGF7 and GM-CSF in fibroblasts (Szabowski et al. 2000). Therefore, it seemed to be convincing that the IL-1 system also has functions in vaginal epithelial cell proliferation and differentiation.

The time-course of gene expression (IL- $1 \alpha$, IL-1 $\beta$, IL-1RI, IL-1RII, IL-1ra and IL-1L1) was examined in vaginas from 60-day-old OVX control mice after a single injection of $\mathrm{E}_{2}$ (Fig. 2A). $\mathrm{E}_{2}$ administration rapidly induced IL-1RI expression within $1 \mathrm{~h}(5 \cdot 1$-fold compared with $0 \mathrm{~h})$; IL-1RI expression subsequently declined slowly. Expression of the other genes was not changed but IL-1L1 expression increased from $24 \mathrm{~h}$, peaking at $36 \mathrm{~h}$ $(43 \cdot 3$-fold). In neoDES vaginas, expression of IL- $1 \alpha$ $(4 \cdot 2$-fold) and IL-1 RII $(30 \cdot 1$-fold $)$ was increased together with high-level expression of IL-1L1 (Fig. 2B). To study the tissue distribution of these factors, epithelium and stroma from neoDES vaginas were separated by incubation in trypsin, followed by dissection and RT-PCR analysis. IL- $1 \alpha$ and IL-1L1 were found to be primarily expressed in the epithelium whereas IL-1RI and IL-1RII were expressed in both epithelium and stroma (Fig. 2C).

To investigate the participation of IL-1 signaling in the neoDES vagina, we tested the activation status of SAPK/JNK, which is one of the downstream factors of IL-1 (Karin et al. 1997). As shown in Fig. 2D, SAPK/JNK (particularly JNK1) was phosphorylated in the neoDES vagina but only slightly phosphorylated in controls. Then, we tested the mRNA expression of KGF and GM-CSF in stromal tissue in the control and neoDES vaginas. In both control and neoDES vaginas, KGF and GM-CSF mRNA were expressed; however, unexpectedly, their expression levels showed no change (Fig. 2E).

\section{IGF-I signaling in the neoDES vagina}

In mouse uterus, locally produced uterine IGF-I mediates the effects of $\mathrm{E}_{2}$ on growth and cell proliferation (Klotz et al. 2002). In the neoDES vagina, IGFBP-2 levels were increased, but IGFBP-3 and IGF-IR levels were decreased (Table 3). These data raised the possibility that the IGF-I pathway is modulated in the neoDES vagina, therefore, we further analyzed this signaling pathway in the vagina. 


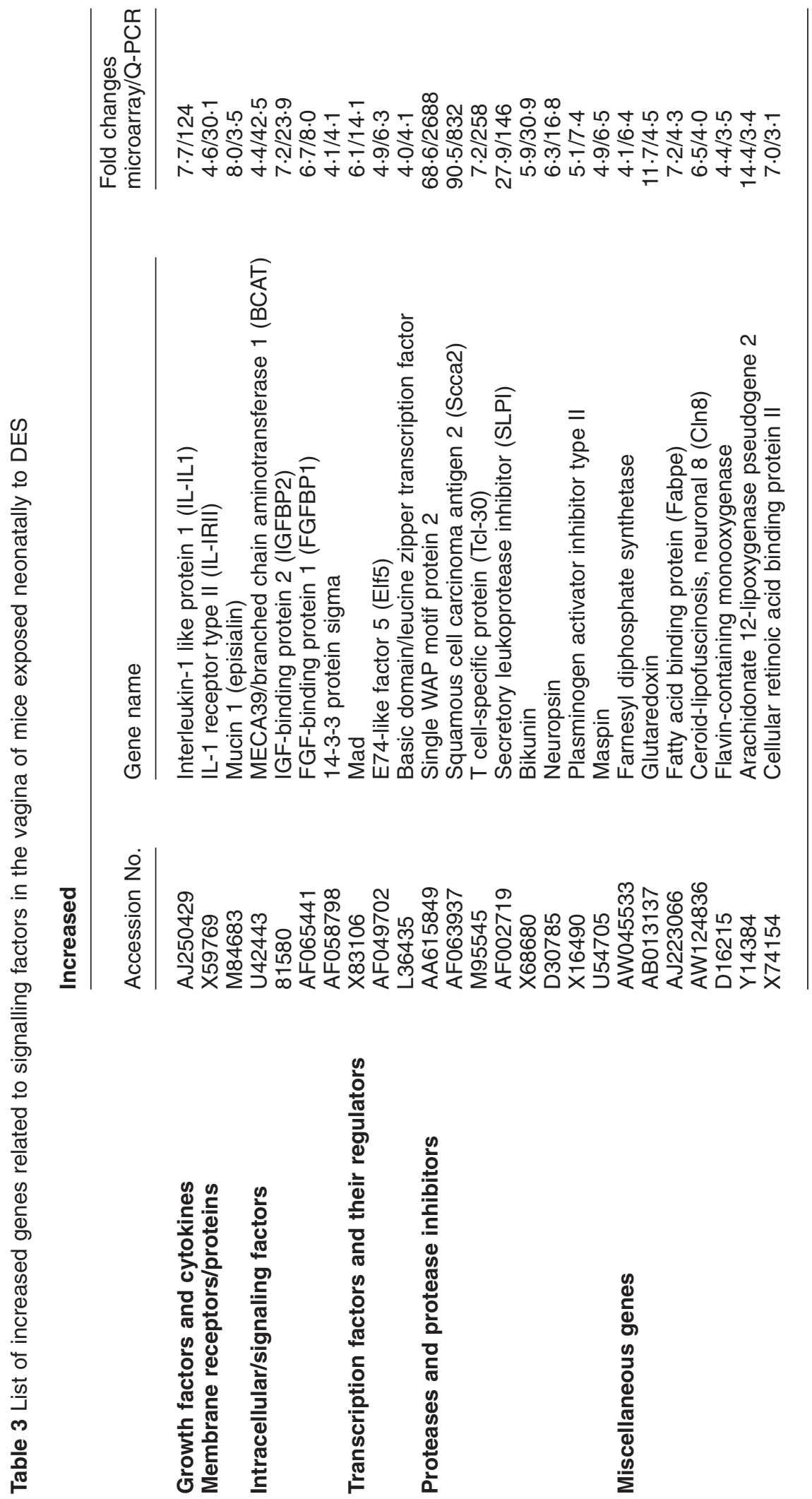



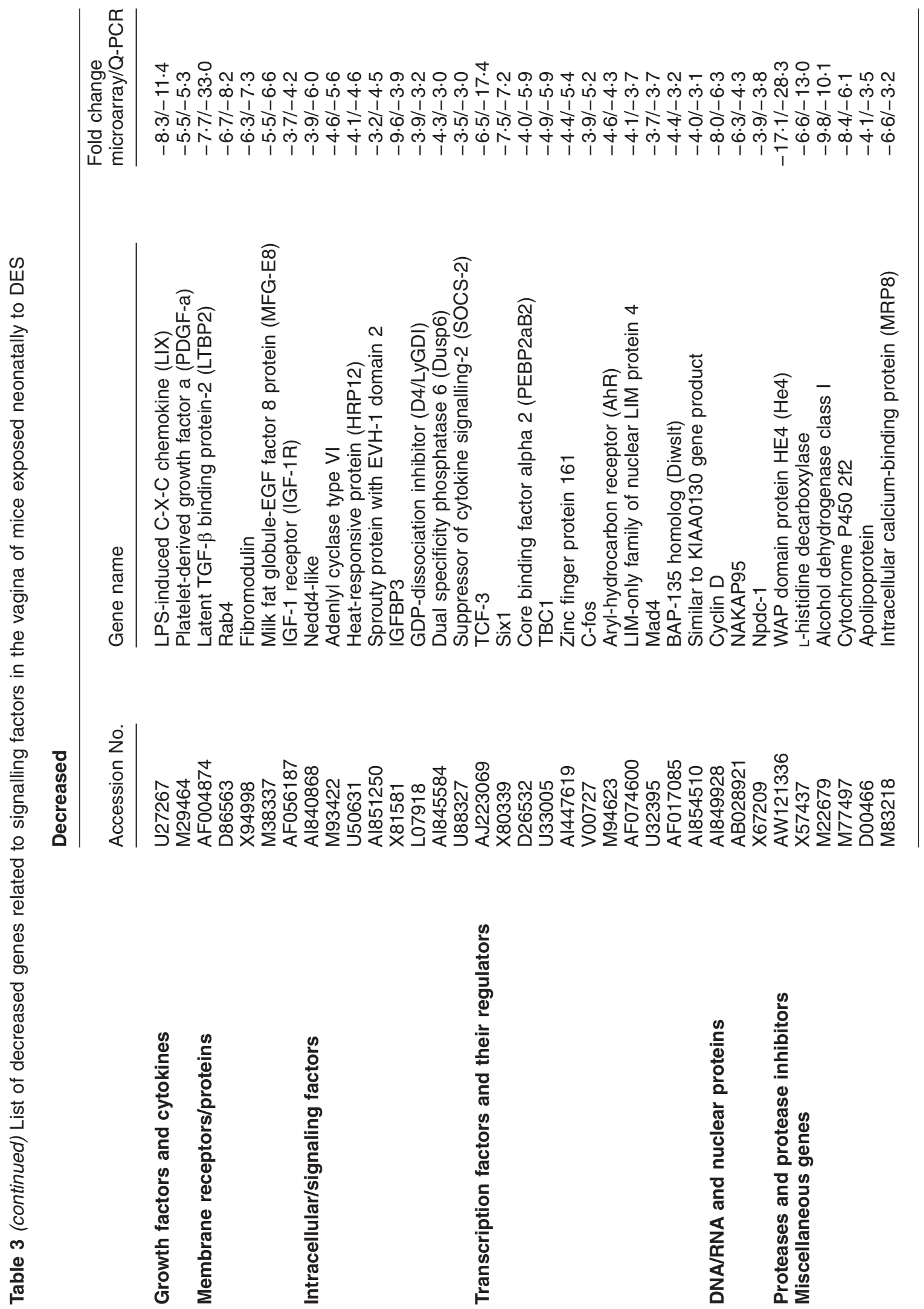

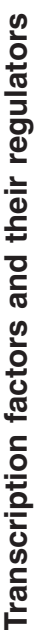

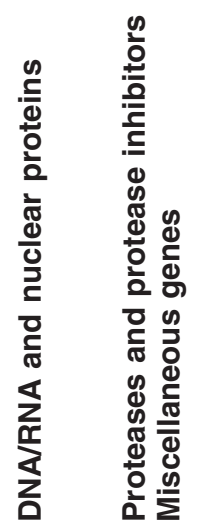


A
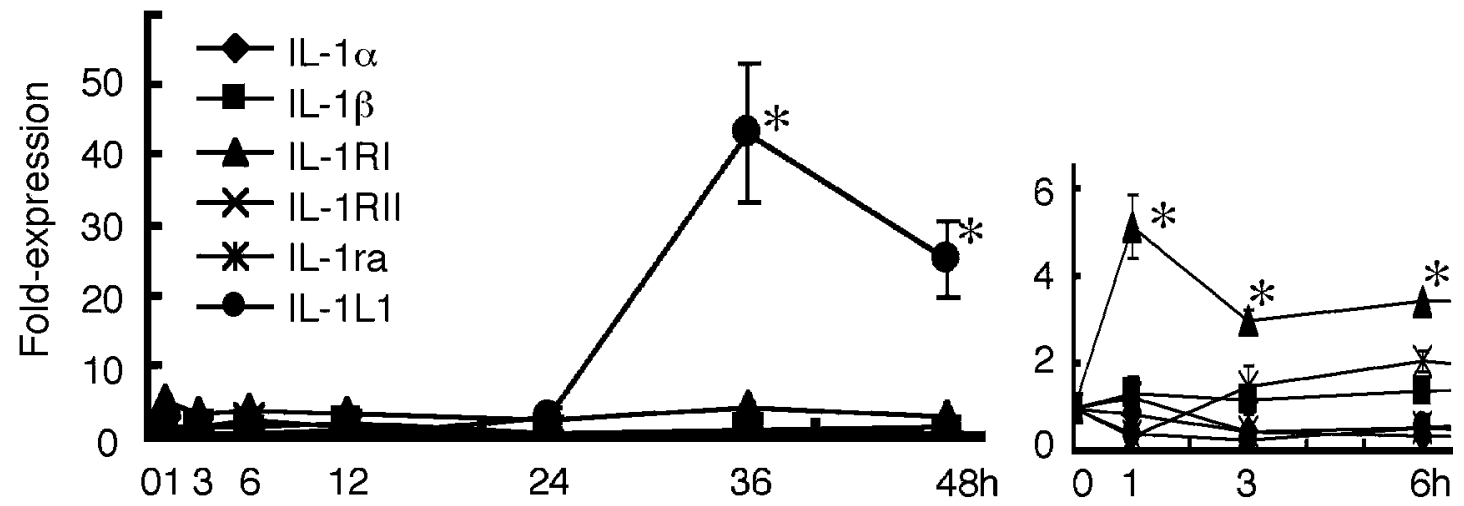

B

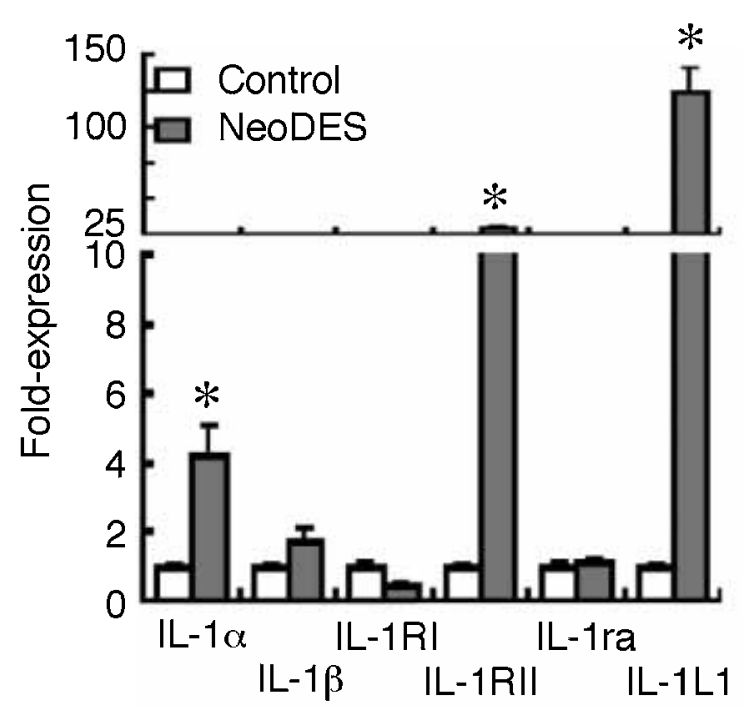

C

E S W

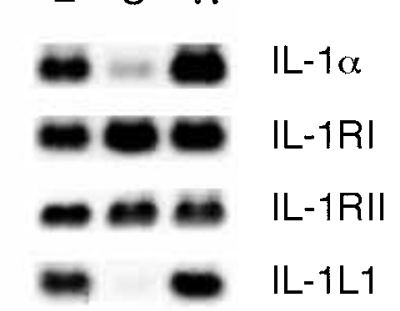

D

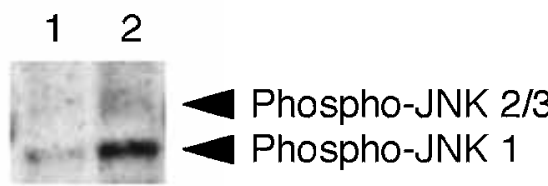

E

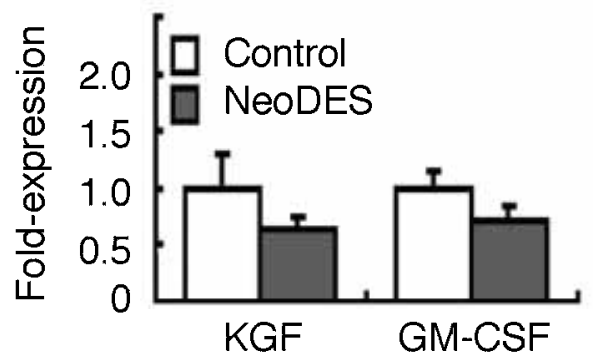

Figure 2 IL-1-related gene expression and its downstream signaling in the mouse vagina.

(A) Time-course analysis of IL-1-related gene expression. Samples were from vaginas of mice 0 (control), 1, 3, 6, 12, 24, 36 and $48 \mathrm{~h}$ after a single injection of $50 \mathrm{ng} \mathrm{E}_{2} / \mathrm{g} \mathrm{BW}$. The right panel shows an enlarged view of the $0-6 \mathrm{~h}$ range of the left panel. More than three mice were used per each group. Error bars represent the standard error. (B) Expression profiles of IL-1-related genes in vaginas of 60-day-old control and neoDES mice. (C) Tissue distribution of IL-1 $\alpha$, IL-RI, IL-1RII and IL-1L1 mRNA expression in the neoDES vagina. E, epithelium; S, stroma; W, whole tissue. (D) Activation status of JNK was detected by anti-phospho-JNK antibody. The samples are from control (lane 1) and neoDES mice (lane 2). (E) Expression of KGF and GM-CSF mRNA in vaginal stromal tissue in control and neoDES vaginas. 
A

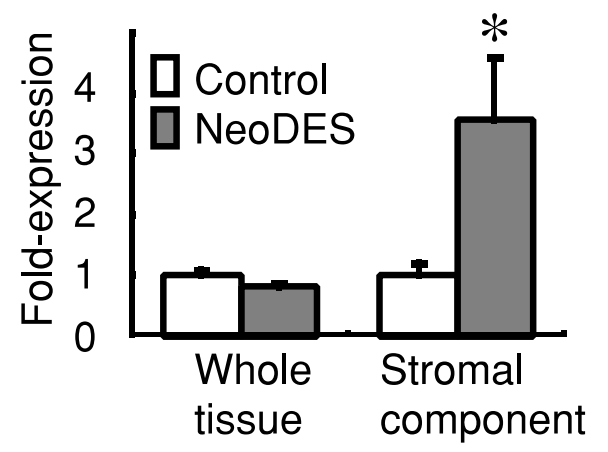

B

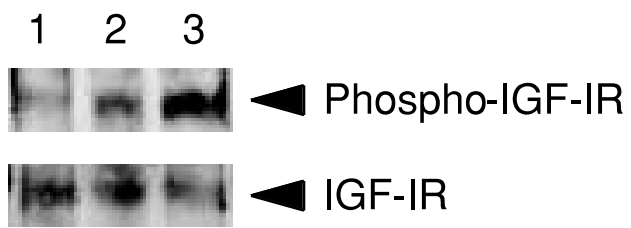

C

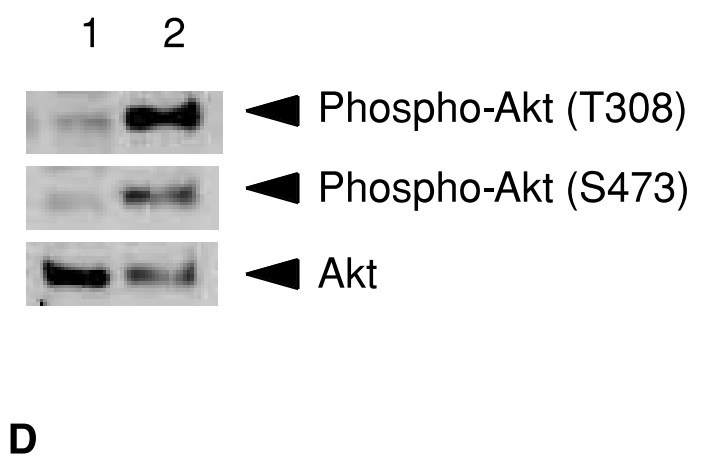

Figure 3 Activation status of the IGF signaling pathway in the neoDES vagina. (A) Expression of IGF-I mRNA in vaginal tissue in control and neoDES vaginas. More than three mice were used in each group. Error bars represent the standard error. (B) Phosphorylation of IGF-IR was detected by anti-phospho-IGF-IR antibody. The samples were from vaginas of OVX mice treated with oil (lane 1), DES (lane 2) and neoDES mice (lane 3). (C) IGF-I-induced phosphorylation of Akt in the adult OVX mouse vagina. The samples were from vaginas of OVX mice treated with saline (lane 1) and long R3 IGF-I (lane 2). (D) Activation status of Akt was detected by anti-phospho-Akt antibodies. The samples were from vaginas of OVX mice treated with oil (lane 1), DES (lane 2) and neoDES mice (lane 3).

IGF-I mRNA level in the whole tissue was not altered between control and neoDES vaginas (Fig. 3A and Miyagawa et al. 2004). However, when compared in the stromal component, IGF-I mRNA level was increased in the neoDES vagina (Fig. 3A). As shown in Fig. 3B, distinct phosphorylation of IGF-IR was detected in the neoDES vagina and it is similar to vaginas of mice treated with DES successively as a positive control. IGF-IR in vaginas of oil-treated control mice showed a low level of phosphorylation, although IGF-IR protein was expressed. To further characterize the factors downstream of IGF-I signaling in the neoDES mouse, we examined the activation status of Akt, which is known as one of the major regulatory factors in IGF-I signaling (Martin et al. 2000). As in the mouse uterus (Klotz et al. 2002), IGF-I administration induced phosphorylation of Akt in vaginas of adult OVX mice (Fig. 3G). Furthermore, we detected Akt activation in the vaginas of
neoDES and DES-treated mice but not in oil-treated controls (Fig. 3D).

\section{Discussion}

We examined the global expressions of mRNAs, focusing on factors involved in cell signaling in the neoDES vagina, which shows persistent vaginal hyperplasia and keratinization (Takasugi et al. 1962, McLachlan et al. 1980, Iguchi 1992). First, we intended to clarify the overall expression patterns of genes in the neoDES vagina which seemed to be useful for further analysis. Using DNA microarray, we found altered expression of several genes in the neoDES vagina compared with controls and detected genes showing altered expression which are candidates for mediating the persistent proliferation and differentiation. Nonetheless, each gene needs to be elucidated in detail; in this report, we 
focused on the two signaling pathways, the IL-1 and IGF-I systems, which are possibly involved in cellular signaling in the vagina.

\section{IL-1 signaling}

The cytokine IL-1 elicits pleiotropic biological effects in various tissues, including the regulation of epidermal differentiation and inflammation in skin (Dinarello 1998). Although the function of IL-1L1 remains undescribed (Barton et al. 2000), its abundant expression in skin and vaginal epithelium suggests that it may be involved in epithelial cell differentiation (Mulero et al. 1999). IL-1L1 expression was elevated $24 \mathrm{~h}$ after $\mathrm{E}_{2}$ administration, similar to other differentiation markers such as CK1 (data not shown). Intriguingly, expression of IL- $1 \alpha$, which showed no change in expression after estrogen stimulation in adult OVX mice, was increased in the neoDES vagina. Although IL- $1 \alpha$ and IL-1L1 may not be estrogen-primed genes, these data suggested that IL-1 signaling has a functional role in the maintenance of epithelial cell differentiation, rather than estrogen-primed cell proliferation in the vagina. The negative regulator of IL-1 signaling, IL-1RII, was also highly expressed in the neoDES vagina. Stimuli that induce IL-1 gene expression in keratinocytes in vitro, also strongly stimulate IL-1RII expression (Groves et al. 1995), and a high level of IL-1RII is expressed in keratinocytes in psoriasis (Groves et al. 1994). Thus, the increased expression of IL-1RII in the neoDES vagina showing ovary-independent stratification and keratinization is not surprising.

IL-1 stimulates the activity of the transcription factors AP-1 and nuclear factor $\kappa \mathrm{B}(\mathrm{NF}-\kappa \mathrm{B})$. These effects are mediated through activation of SAPK/ $\mathrm{JNK}$ and inhibitor of NF- $\mathrm{KB}$ kinases respectively. In the present study, we found that JNK1 was activated in the neoDES vagina. IL-1 induced in the epidermis is known to regulate KGF and GM-CSF in the dermis through AP-1 (Szabowski et al. 2000). We supposed that there is the presence of similar regulation by IL-1 signaling in both epidermis and vaginal epithelium. KGF and GM-CSF were expressed in both control and neoDES vaginas and their expression levels were not different. Therefore, it is unlikely that KGF and GM-CSF have direct positive roles in epithelial proliferation and differentiation in the vagina. Actually, estrogen treatment did not induce mRNA expression of $\mathrm{KGF}$ and GM-CSF in the vagina (Masui et al. 2003, Miyagawa et al. 2004), and KGF-null mice are fertile and morphologically normal (Guo et al. 1996). This is in contrast to skin, where KGF effects are crucial. Defects in the skin and hair follicles were observed in KGF-null mice (Guo et al. 1996). Overexpression of KGF in transgenic mice induced altered epidermal growth and differentiation, including wrinkled skin and increased epidermal thickness (Guo et al. 1993). Thus, KGF contributed less to vaginal epithelial differentiation than to that of skin, however, non-physiological amounts of KGF treatment may affect vaginal keratinocyte differentiation. It was reported that neonatally KGF-treated mouse vaginas showed persistent epithelial differentiation (Hom et al. 1998). Although we indicated differences between skin and vagina, both showed stratification and keratinization in the epithelium, and the roles of the IL-1 system, KGF, GM-CSF and also JNK1 phosphorylation in the vagina remain unknown.

\section{IGF-I signaling}

In the mouse uterus and vagina, epithelial proliferation appears to be a paracrine event mediated by stromal soluble factors, but these factors have not been identified (Cooke et al. 1997, Buchanan et al. 1998). Although the stromal contribution to persistent activation of vaginal epithelium is less than that of normal $\mathrm{E}_{2}$-induced action in the vagina (Cunha et al. 1977, Miyagawa et al. 2004), some stromal factors must be contributing to the persistent activation in the neoDES vagina. Such candidates were not directly detected on DNA array data, which is probably due to the conservative adoption of 3-fold differences in the present microarray analysis. In the present study, IGF-I mRNA derived from vaginal stroma was increased by estrogen treatment as compared with controls but was not changed at whole tissue levels. This IGF-I signaling may be enhanced by its growth factor-binding factors, which influence growth factor availability and activity, because IGFBP-3 levels were decreased. As a result, IGF-IR is phosphorylated, leading to Akt phosphorylation, which suggests that IGF-I signaling is active in the neoDES vagina, where it may regulate several biological processes. Of course, other growth factors have a potential involvement 
in persistent signaling in the neoDES vagina. A large amount of epithelial cells makes it difficult to detect genes derived from stroma. We need to further analyze the gene expression from the stromal component. Still, IGF-I is one of the candidates of stromal factors which mediate the vaginal epithelial cell proliferation.

We found that IGFBP-3 was downregulated whereas IGFBP-2 was highly expressed in the neoDES vagina. IGFBP-2 generally regulates IGF-induced action by binding to IGFs. Although IGFBP-2 inhibits IGF action, IGFBP-2 is overexpressed in various malignant tissues, often correlating with tumorigenesis (Zumkeller 2001). It should be noted that some of the effects of IGFBP-2 overexpression on cell proliferation are proposed to be independent of IGFs (Slootweg et al. 1995, Badinga et al. 1999). Therefore, the elevated levels of IGFBP-2 we detected could be directly involved in the inappropriate epithelial proliferation in neoDES vaginas.

\section{Akt phosphorylation}

In the present study, we found that Akt was phosphorylated by estrogen in the mouse vagina, which was similar to the uterus, as described in the demonstration that Akt was a functional mediator of estrogen-induced cell proliferation (Klotz et al. 2002). In addition, expression of active Akt in MCF-7 cells results in estrogen-independent tumor growth (Faridi et al. 2003). Akt promotes cell survival through phosphorylation and inactivation of several pro-apoptotic targets, such as Bad and forkhead transcription factors which indirectly affect NF-кB and p53 (Brunet et al. 1999, Downward 1999, Vivanco \& Sawyers 2002). These observations indicate that $\mathrm{Akt}$ is involved in estrogen-dependent and/or -independent cell proliferation and even carcinogenesis. The present study showed that Akt phosphorylation occurred in the neoDES vagina even in the absence of estrogen stimulation by OVX, and it may be involved not only in the persistent cell proliferation but also in carcinogenesis in the neoDES vagina later in life.

\section{Other cellular events in the neoDES vagina}

We detected additional genes that are expected to be involved in vaginal epithelial cell differentiation. For example, various proteases and protease inhibitors were highly expressed in neoDES vaginas. The protease inhibitors are involved in keratinocyte differentiation or epidermal wound repair (Tamechika et al. 1996, Gui et al. 1999, Katz \& Taichman 1999, Li et al. 2000, Zhu et al. 2002). The serine protease, neuropsin, is expressed in superficial layers of keratinized epithelium in the mouse vagina (Katsu et al. 2002). These genes are thought to be involved in fibrinolysis, inflammation, cell migration and growth factor proteolysis by regulating the activity of other proteases (Travis \& Salvesen 1983, Carrell et al. 1989, Potempa et al. 1994). Thus, proteases and protease inhibitors identified in this study may be involved in the differentiation of mouse vaginal epithelium.

\section{Application to DES syndrome in the human}

Although estimates vary, about four million women have been exposed to DES during pregnancy (Newbold 1993). Epidemiological studies indicate an increased incidence of breast cancer, squamous neoplasia of the cervix and vagina, and vaginal clear-cell adenocarcinoma in women exposed to DES in utero (Herbst 2000, Hatch et al. 2001, Palmer et al. 2002). In addition to the aberrant cellular signal transduction, a hypothesis for the association between DES and high-grade disease is that DES in utero possibly induced permanent alteration in the immune system. Profound alterations in the immune system, especially of natural killer cells, were found in mice treated neonatally with DES (Kalland 1982). In the present study, we demonstrated that expression of genes related to the immune system was decreased, which could lead to a locally reduced immune function in neoDES mice. In humans, permanent alterations in the immune system may lead to a reduced ability to fight off a genital infection, such as human papilloma virus, thereby increasing the susceptibility to secondary risk factors for carcinogenesis. Further characterization of the perinatally estrogen-exposed mouse model is needed to fully understand the potential risk of the carcinogenic effects of estrogens.

In conclusion, we characterized the gene expression pattern of the neoDES vagina. In such vaginas, the IGF-I signaling cascade was activated, resulting in Akt phosphorylation. Aberrant Akt phosphorylation is one of the key regulators of the vagina showing persistent proliferation. We also 
found JNK-1 phosphorylation status and expression of various genes were changed. These complicated expressions of genes and protein phosphorylation status lead to vaginal changes and the present findings give insight into the persistent activation in vaginas from neonatally DES-exposed mice.

\section{Acknowledgements}

We are grateful to Dr Bruce Blumberg, Department of Developmental and Cell Biology, University of California at Irvine, for his critical readings of the manuscript. This work was supported in part by a Grant-in-Aid for Scientific Research from the Ministry of Education, Culture, Sports, Science and Technology of Japan, and a Health Sciences Research Grant from the Ministry of Health, Labor and Welfare, and a research grant from the Ministry of the Environment, Japan.

\section{References}

Badinga L, Song S, Simmen RC, Clarke JB, Clemmons DR \& Simmen FA 1999 Complex mediation of uterine endometrial epithelial cell growth by insulin-like growth factor-II (IGF-II) and IGF-binding protein-2. Fournal of Molecular Endocrinology 23 277-285.

Barton JL, Herbst R, Bosisio D, Higgins L \& Nicklin MJ 2000 A tissue specific IL-1 receptor antagonist homolog from the IL-1 cluster lacks IL-1, IL-1ra, IL-18 and IL-18 antagonist activities. European Foumal of Immunology $\mathbf{3 0} 3299-3308$.

Bosch FX, Leube RE, Achtstatter T, Moll R \& Franke WW 1988 Expression of simple epithelial type cytokeratins in stratified epithelia as detected by immunolocalization and hybridization in situ. Fournal of Cell Biology 106 1635-1648.

Brunet A, Bonni A, Zigmond MJ, Lin MZ, Juo P, Hu LS, Anderson MJ, Arden KC, Blenis J \& Greenberg ME 1999 Akt promotes cell survival by phosphorylating and inhibiting a Forkhead transcription factor. Cell 96 857-868.

Buchanan DL, Kurita T, Taylor JA, Lubahn DB, Cunha GR \& Cooke PS 1998 Role of stromal and epithelial estrogen receptors in vaginal epithelial proliferation, stratification, and cornification. Endocrinology 139 4345-4352.

Carrell RW, Aulak KS \& Owen MC 1989 The molecular pathology of the serpins. Molecular Biology and Medicine 6 35-42.

Cooke PS, Buchanan DL, Young P, Setiawan T, Brody J, Korach KS, Taylor J, Lubahn DB \& Cunha GR 1997 Stromal estrogen receptors mediate mitogenic effects of estradiol on uterine epithelium. PNAS 94 6535-6540.

Cui CY, Aragane Y, Maeda A, Piao YL, Takahashi M, Kim LH \& Tezuka T 1999 Bikunin, a serine protease inhibitor, is present on the cell boundary of epidermis. Fournal of Investigative Dermatology 113 182-188.

Cunha GR, Lung B \& Kato K 1977 Role of the epithelial-stromal interaction during the development and expression of ovary-independent vaginal hyperplasia. Developmental Biology 56 $52-67$.
Dinarello CA 1998 Interleukin-1, interleukin-1 receptors and interleukin-1 receptor antagonist. International Reviewes of Immunology 16 457-499.

Downward J 1999 How BAD phosphorylation is good for survival. Nature Cell Biology 1 E33-E35.

Faridi J, Wang L, Endemann G \& Roth RA 2003 Expression of constitutively active Akt-3 in MCF-7 breast cancer cells reverses the estrogen and tamoxifen responsivity of these cells in vivo. Clinical Cancer Research 9 2933-2939.

Forsberg JG 1979 Developmental mechanism of estrogen-induced irreversible changes in the mouse cervicovaginal epithelium. National Cancer Institute Monographs 51 41-56.

Groves RW, Sherman L, Mizutani H, Dower SK \& Kupper TS 1994 Detection of interleukin-1 receptors in human epidermis. Induction of the type II receptor after organ culture and in psoriasis. American Fournal of Pathology 145 1048-1056.

Groves RW, Giri J, Sims J, Dower SK \& Kupper TS 1995 Inducible expression of type 2 IL-1 receptors by cultured human keratinocytes. Implications for IL-1-mediated processes in epidermis. Fournal of Immunology 154 4065-4072.

Guo L, Yu QC \& Fuchs E 1993 Targeting expression of keratinocyte growth factor to keratinocytes elicits striking changes in epithelial differentiation in transgenic mice. EMBO fournal 12 973-986.

Guo L, Degenstein L \& Fuchs E 1996 Keratinocyte growth factor is required for hair development but not for wound healing. Genes and Development 10 165-175.

Hatch EE, Herbst AL, Hoover RN, Noller KL, Adam E, Kaufman RH, Palmer JR, Titus-Ernstoff L, Hyer M, Hartge P \& Robboy SJ 2001 Incidence of squamous neoplasia of the cervix and vagina in women exposed prenatally to diethylstilbestrol (United States). Cancer Causes and Control 12 837-845.

Herbst AL 2000 Behavior of estrogen-associated female genital tract cancer and its relation to neoplasia following intrauterine exposure to diethylstilbestrol (DES). Gynecologic Oncology 76 147-156.

Herbst AL, Ulfelder H \& Poskanzer DC 1971 Adenocarcinoma of the vagina. Association of maternal stilbestrol therapy with tumor appearance in young women. New England Fournal of Medicine $\mathbf{2 8 4}$ 878-881.

Hom YK, Young P, Thomson AA \& Cunha GR 1998 Keratinocyte growth factor injected into female mouse neonates stimulates uterine and vaginal epithelial growth. Endocrinology 139 3772-3779.

Iguchi T 1992 Cellular effects of early exposure to sex hormones and antihormones. International Review of Cytology 139 1-57.

Ishigami A, Kuramoto M, Yamada M, Watanabe K \& Senshu T 1998 Molecular cloning of two novel types of peptidylarginine deiminase cDNAs from retinoic acid-treated culture of a newborn rat keratinocyte cell line. FEBS Letters 433 113-118.

Kalland T 1982 Long-term effects on the immune system of early life exposure to diethystilbestrol. In Environment Factors in Human Growth and Development, pp 217-239. Eds VR Hunt, MK Smith \& D Worth. New York: Cold Spring Harbor Laboratory.

Karin M, Liu Z \& Zandi E 1997 AP-1 function and regulation. Current Opinion in Cell Biology 9 240-246.

Katsu Y, Takasu E \& Iguchi T 2002 Estrogen-independent expression of neuropsin, a serine protease in the vagina of mice exposed neonatally to diethylstilbestrol. Molecular and Cellular Endocrinology 195 99-107.

Katz AB \& Taichman LB 1999 A partial catalog of proteins secreted by epidermal keratinocytes in culture. Fournal of Investigative Dermatology 112 818-821.

Kim IG, Gorman JJ, Park SC, Chung SI \& Steinert PM 1993 The deduced sequence of the novel protransglutaminase $\mathrm{E}$ (TGase3) of human and mouse. Fournal of Biological Chemistry 268 12682-12690.

Klotz DM, Hewitt SC, Ciana P, Raviscioni M, Lindzey JK, Foley J, Maggi A, DiAugustine RP \& Korach KS 2002 Requirement of 
estrogen receptor-alpha in insulin-like growth factor-I (IGF-I)-induced uterine responses and in vivo evidence for IGF-I/estrogen receptor cross-talk. Fournal of Biological Chemistry 277 8531-8537.

Li F, Goncalves J, Faughnan K, Steiner MG, Pagan-Charry I, Esposito D, Chin B, Providence KM, Higgins PJ \& Staiano-Coico L 2000 Targeted inhibition of wound-induced PAI-1 expression alters migration and differentiation in human epidermal keratinocytes. Experimental Cell Research 258 245-253.

Lockhart DJ, Dong H, Byrne MC, Follettie MT, Gallo MV, Chee MS, Mittmann M, Wang C, Kobayashi M, Horton H \& Brown EL 1996 Expression monitoring by hybridization to high-density oligonucleotide arrays. Nature Biotechnology 14 1675-1680.

McLachlan JA, Newbold RR \& Bullock BC 1980 Long-term effects on the female mouse genital tract associated with prenatal exposure to diethylstilbestrol. Cancer Research 40 3988-3999.

Marselos M \& Tomatis L $1992 a$ Diethylstilboestrol: I, Pharmacology, toxicology and carcinogenicity in humans. European fournal of Cancer 28A 1182-1189.

Marselos M \& Tomatis L $1992 b$ Diethylstilboestrol: II, pharmacology, toxicology and carcinogenicity in experimental animals. European Fournal of Cancer 29A 149-155.

Martin MB, Franke TF, Stoica GE, Chambon P, Katzenellenbogen BS, Stoica BA, McLemore MS, Olivo SE \& Stoica A 2000 A role for Akt in mediating the estrogenic functions of epidermal growth factor and insulin-like growth factor I. Endocrinology 141 4503-4511.

Masui F, Matsuda M \& Mori T 2003 Vitamin A prevents the irreversible proliferation of vaginal epithelium induced by neonatal injection of keratinocyte growth factor in mice. Cell and Tissue Research 311 251-258.

Miyagawa S, Katsu Y, Watanabe H \& Iguchi T 2004 Estrogen-independent activation of erbBs signaling and estrogen receptor alpha in the mouse vagina exposed neonatally to diethylstilbestrol. Oncogene 23 340-349.

Mulero JJ, Pace AM, Nelken ST, Loeb DB, Correa TR, Drmanac R \& Ford JE 1999 IL1HY1: a novel interleukin-1 receptor antagonist gene. Biochemical and Biophysical Research Communications $263702-706$.

Newbold RR 1993 Gender-related behavior in women exposed prenatally to diethylstilbestrol. Environmental Health Perspectives 101 208-213.

Palmer JR, Hatch EE, Rosenberg CL, Hartge P, Kaufman RH, Titus-Ernstoff L, Noller KL, Herbst AL, Rao RS, Troisi R, Colton T \& Hoover RN 2002 Risk of breast cancer in women exposed to diethylstilbestrol in utero: preliminary results (United States). Cancer Causes and Control 13 753-758.
Pastan I \& Willingham MC 1983 Receptor-mediated endocytosis: coated pits, receptosomes and the golgi. Trends in Biochemical Sciences 8 250-254.

Potempa J, Korzus E \& Travis J 1994 The serpin superfamily of proteinase inhibitors: structure, function, and regulation. Fournal of Biological Chemistry 269 15957-15960.

Quaife CJ, Findley SD, Erickson JC, Froelick GJ, Kelly EJ, Zambrowicz BP \& Palmiter RD 1994 Induction of a new metallothionein isoform (MT-IV) occurs during differentiation of stratified squamous epithelia. Biochemistry 33 7250-7259.

Schroder JM 1995 Cytokine networks in the skin. Fournal of Investigative Dermatology 105 20S-24S.

Slootweg MC, Ohlsson C, Salles JP, de Vries CP \& Netelenbos JC 1995 Insulin-like growth factor binding proteins-2 and -3 stimulate growth hormone receptor binding and mitogenesis in rat osteosarcoma cells. Endocrinology 136 4210-4217.

Szabowski A, Maas-Szabowski N, Andrecht S, Kolbus A, Schorpp-Kistner M, Fusenig NE \& Angel P 2000 c-Jun and JunB antagonistically control cytokine-regulated mesenchymal-epidermal interaction in skin. Cell $\mathbf{1 0 3} 745-755$.

Takasugi N, Bern H \& DeOme K 1962 Persistent vaginal cornification in mice. Science 138 438-439.

Tamechika I, Itakura M, Saruta Y, Furukawa M, Kato A, Tachibana S \& Hirose S 1996 Accelerated evolution in inhibitor domains of porcine elafin family members. Fournal of Biological Chemistry 271 7012-7018.

Travis J \& Salvesen GS 1983 Human plasma proteinase inhibitors. Annual Review of Biochemistry 52 655-709.

Vivanco I \& Sawyers CL 2002 The phosphatidylinositol 3-kinase AKT pathway in human cancer. Nature Review. Cancer 2 489-501.

Watanabe H, Suzuki A, Kobayashi M, Takahashi E, Itamoto M, Lubahn DB, Handa H \& Iguchi T 2003 Analysis of temporal changes in the expression of estrogen-regulated genes in the uterus. Fournal of Molecular Endocrinology 30 347-358.

Zhu J, Nathan G, Jin W, Sim D, Ashcroft GS, Wahl SM, Lacomis L, Erdjument-Bromage H, Tempst P, Wright CD \& Ding A 2002 Conversion of proepithelin to epithelins: roles of SLPI and elastase in host defense and wound repair. Cell $111867-878$.

Zumkeller W 2001 IGFs and IGFBPs: surrogate markers for diagnosis and surveillance of tumour growth? Molecular Pathology 54 285-288.

Received in final form 10 February 2004

Accepted 17 February 2004

Made available online as an

Accepted Preprint 8 March 2004 